\title{
A Cross-disciplinary Study on Evaluative Strategies in Research Articles Conclusion Sections
}

\section{Maryam Farnia ${ }^{1 *}$, Masoud Saeedi ${ }^{1}$, \& Zahra Ataei ${ }^{1}$}

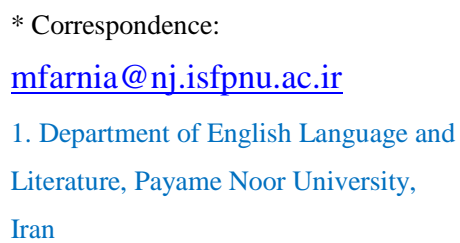

Received: 26 May 2019

Revision: 30 October 2019

Accepted: 20 December 2019

Published online: 20 March 2020

\begin{abstract}
In academia, different disciplines tend to represent themselves, their writers, and their readers in unique ways. To be able to probe into such crossdisciplinary discursive variations, the present cross-disciplinary study used Martin and White's appraisal framework incorporating lexico-grammar and language evaluation strategies to explore the linguistic construal of evaluative stance in the conclusion section of academic research articles. To this end, a corpus of 160 research articles randomly selected from English international journals of psychology as a representative of soft sciences and industrial engineering as a representative of hard sciences were examined in the light of Martin and White's scheme, with a focus on graduation. To code the data, UAM Corpus Tool was used for the ease of descriptive analyses. In general, the findings indicated that the number of graduation words and graduation types were significantly higher in the hard science corpus compared to the soft science one, suggesting that the authors of hard science articles mainly attempted to express their appreciation and judgment and report the fluctuation of a specific feature in their findings.
\end{abstract}

Keywords: appraisal theory, conclusion section, graduation, hard science, soft science 


\section{Introduction}

This study focuses on graduation as one aspect of evaluative language that writers use in developing research articles (Martin \& White, 2005). To this aim, the investigation explores the ways in which English writers take in writing the conclusion sections of research articles in soft and hard science disciplines in order to enhance professional writing by pinpointing the differences across two disciplines.

From among studies done on evaluative language in research articles and as stated above, some have explored this feature of academic text in different sections of research. Despite its importance, however, the evaluative language of discussion/conclusion sections has not been accorded due attention by researchers and this dearth of research is manifest in the plethora of nonnative bachelor or master student publications which lack well-written, effective discussion/conclusion sections and therefore are of little scientific quality. In particular, it seems that the novice authors of these papers fail to convince the reader as to the significance of the findings and their contribution to the available literature. In the following section, the theoretical framework conceptualizing the evaluative language which is of central importance to the present research will be expounded.

Originally developed in Australian schools of educational linguistics and literacy intervention (Oteíza, 2017) and motivated by systemic functional linguistics (Halliday, 1994), Martin and White (2005) proposed a framework of appraisal incorporating the linguistic means through which writers and speakers manifest their attitudes, partake in propositions, and categorize meaning assessment. In his systemic functional linguistic theory, Halliday (1994) viewed language as a tool for making meaning. Meaning making, assumes Halliday, can be broadly characterized in terms of three metafunctions: (a) 'ideational' meaning through which a language construes the world of experience by making sense of the reality, (b) 'interpersonal' meaning by means of which speakers/writers establish and maintain personal relationships with people, and (c) 'textual' meaning by which these ideational and interpersonal meanings are linguistically realized and organized into coherent spoken or written texts. Along the same lines, the 'evaluative meanings' in the appraisal framework provide mechanisms through which the interpersonal metafunctions operate. Precisely, such mechanisms display how speakers/writers express their feelings, tastes, and opinions with varying degrees of intensity and directness, construe more or less contentious or warrantable propositions, and agree with or refute value positions existing in a particular communicative context (White, 2002).

As proposed by Martin (1997), within the interpersonal metafunction, the abovementioned appraisal resources function in tandem with two other interpersonal systems: communicative resources through which speakers or writers effectuate such speech functions as asserting, questioning, responding, commanding, advising, and offering, and meaning systems by means of which speakers indicate how intimate a relationship they have with their interlocutors. This purpose is achieved by using slangs, jargons, specialist terms, and the informal lexis associated with social intimacy. As such, the model provides a full account of the interpersonal functions of a text, i.e., social roles, identities, and relationships enacted through a text, which concurrently deal with patterns in the speech functions effectuated, in the way 'involvement' is managed, and, finally, in the use of the evaluative orientations treated under the umbrella term 'appraisal' (White, 1998).

The major benefit accrued from using Martin and White's (2005) scheme for text analysis is that it provides discourse analysts with an effective research tool for more efficiently understanding the evaluative resources and the subjective positions, enabling them to arrive at a new area of interpersonal meaning (Liu, 2010). Specifically, it deals with the interpretation of interpersonal meaning and the subjective evaluative stance of the writers/speakers in texts regarding the content they present and the audience they address (Martin \& White, 2005). This analytical approach, notes Wu (2013), explores and explains the ways through which languages could be able to express evaluative stance and construct textual personas and deal with interpersonal positioning and relationships. Figure 1 shows the components of this multidimensional model, namely, 'attitude', 'engagement', and 'graduation.' As the focus of this study, only graduation will be explained briefly. 


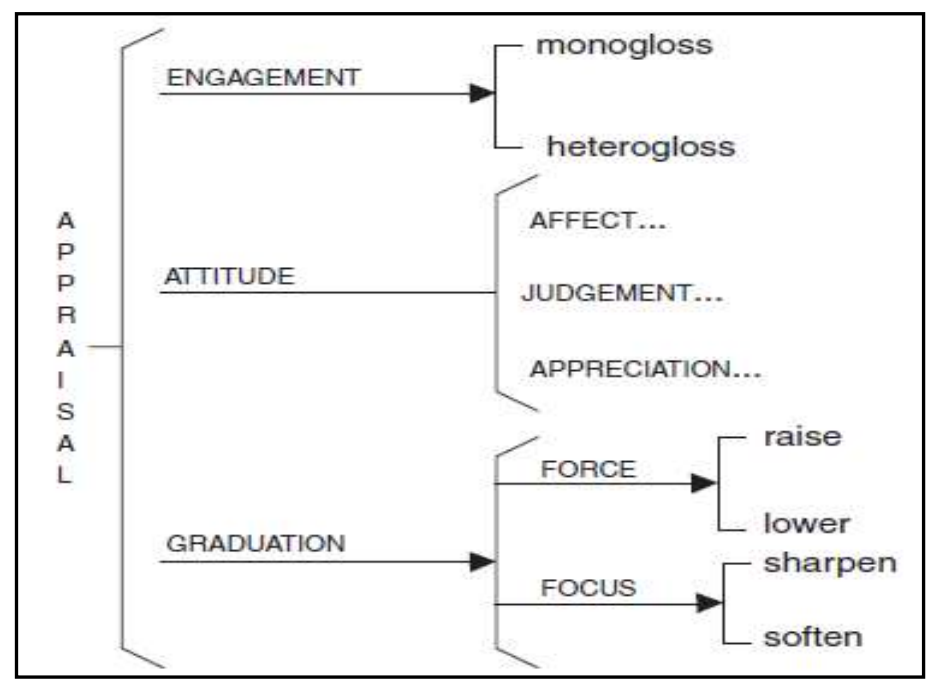

Figure 1. Overview of appraisal resources (adopted from Martin \& White, 2005)

'Graduation' is a key aspect of interpersonal meaning-making function and refers to the extent to which a speaker/hearer invests in his or her in-text propositions. This parameter of the model is conceptualized with reference to the notions of 'force', that is, meanings through which propositions are strengthened or mitigated, and 'focus', that is, meanings by which the boundaries of semantic categories can be blurred or highlighted. In other words, by means of graduation resources speakers raise or lower force or volume of their utterance or by which they blur or sharpen the focus of semantic categorizations of their communications (Martin \& White, 2005).

Graduation through focus, according to Martin and White (2005, p.137), is applicable to non-scalable, that is, clearly defined, either-or categories where membership is determined with reference to "some combination of sufficient and necessary conditions." Martin and White (2005) assert that through 'focus' a speaker/hearer can up-scale, or downscale a certain specification by using words and phrases like real and sort of, respectively. However, graduation, Martin and White note, is not limited to non- scalable or 'experiential' categories. On the contrary, they assume that some categories are gradable according to intensity and prototypicality can also be graded. Attitudinal, naturally scalable terms, Martin and White add, can also be graduated. They present the term upset to point out that such words can be graduated in terms of both 'intensity' (e.g., slightly upset), and 'prototypicality'(e.g., I'm feeling kind of upset).

The second major sub-category of graduation, namely, 'force', is further subdivided into 'intensity' and 'quantity' of a thing or process. Here, intensification refers to the scaling of qualities (e.g., slightly foolish), processes (e.g., This slightly hindered us), and the verbal modalities of likelihood, usuality, inclination, and obligation (e.g., it's just possible that...). Quantification, on the other hand, applies to entities. Such assessments imprecisely measure the number (e.g., a few miles), and the presence or mass of entities with reference to their size, weight, distribution, or proximity (e.g., small amount; nearby mountain) (Martin \& White, 2005). Afterwards, quantity of a process can be reproduced in relation to distance or scope in time or space. The focus system is divided into 'sharpening' or 'softening' of attitudinal meaning (Martin \& Rose, 2007).

Although several studies have addressed the language of evaluation, to date, as of writing this article, no crossdisciplinary studies have specifically drawn upon Martin and White's (2005) appraisal framework to comparatively examine the use of evaluative language in research article conclusion sections across soft and hard sciences. In the following sections, statement of the problem as well as a review of previous studies based on appraisal model in general and graduation resources in particular are explained.

\subsection{Statement of the Problem}

As noted above, a review of previous research shows that Martin and White's (2005) appraisal model can be instrumental in exploring the use of evaluation of graduation in academic writing and specifically research articles. Even so, to the researchers' best of knowledge, to date as of writing this article there has not been any attempt to apply this appraisal subsystem to the conclusion section of research articles. Besides, there seems to be a scarcity of cross disciplinary studies on the use of evaluation in terms of graduation in diverse disciplines, i.e. soft vs. hard science. 
Accordingly, the present research was carried out to cover the existing gap in the literature and advance current body of findings by analyzing the use of evaluative strategies in the conclusion section of research articles in psychology and industrial engineering as representing soft and hard sciences, respectively..

\section{Literature Review}

As a recognized line of research in the academic context, written texts have been studied as a means of evaluation and interaction (Liu, 2013). It is posited that academic writing as a 'persuasive endeavor' (Hyland, 2011, p.15) not only produces texts with an external reality, but also uses language to acknowledge, construct, and negotiate social interactions. The centrality of evaluative language has prompted many researchers to investigate its use in different written genres, such as research articles (e.g., Jalilifar, Bardideh \& Shooshtari, 2018; Jalilifar, Hayati, \& Mashhadi, 2012; Millán, 2014), movie reviews (e.g., Taboada, Carretero, \& Hinnell, 2014), book reviews (e.g., Alcaraz-Ariza, 2002), students' argumentative writings (e.g., Liu, 2013; Liu \& McCabe, 2018; Liu \& Thompson, 2009; Mori, 2017; Myskow \& Ono, 2018; Ngo \& Unworth, 2015; Wu \& Alison, 2003), university lectures (e.g., Bellés-Fortuño, 2017) as well as spoken discourse (e.g., Fernandes, 2011; Llinares, 2015; Põldvere, Matteo, \& Carita, 2016), and translation (Munday, 2015), or biography (Su \& Hunston, 2019), to name a few. Appraisal framework is advantageous in two major aspects: Initially, it is located at the discourse semantic level of language. Just as Thompson and Yiyun (1991) noted, evaluation is best seen as operating at discourse level of text rather than at the grammatical level of the clause. Secondly, the theory provides a complete, detailed, and systematic typology for studying evaluations. For these reasons, Appraisal Theory was considered the most effective for the purpose of the present study.

In academia, each discipline tends to represent itself, its writers, and its readers in its own unique way (Akinci, 2016), and writers attempt to "offer a credible representation of themselves and their work by claiming solidarity with readers, evaluating their material... acknowledging alternative views...negotiating social relations" (Hyland, 2005, p.173). To elucidate cross disciplinary differences, some scholars used hardness or softness as the criterion for designating social science and humanities as soft and natural science as hard using different methodology and research foci (Johns, Chapman, \& Woods, 1972). The distinction between soft and hard science was identified in previous studies based on the dimension (Biglan, 1973), relationship between writer and the audience (Hyland, 2008; Hyland \& Tse, 2004), and word combinations (Durrant, 2017). While research articles in soft disciplines are developed to build a relationship between writer and the reader (Hyland \& Tse, 2004), the hard science research articles are largely cumulative and expected to withstand the rigors of falsifiability by the public (Hyland, 2008).

Among relevant studies on academic publications with a focus on graduation resources, Mei and Allison (2003) studied appraisal in forty essays collected from undergraduate students. The focus of their study was how students negotiate evaluative meanings in the argument they made. Their findings showed that students employed different trends of engagement resources with a combination with attitude and graduation resources in their argumentative essays.

Also, Jalilifar, Hayati, and Mashhadi (2012) examined the introduction section of English research articles published by Iranian and international writers. Eighty research articles introduction sections from 8 Iranian and international journals in the field of English language teaching were analyzed under Martin and Rose's (2007) appraisal framework. Their research findings showed that the international writers employed explicit attitude and graduation resources more significantly than Iranian writers. As Jalilifar et al. (2012) put it, writers of international articles tend to satisfy the reader by employing proper structure and language devices. However, the Iranian writers used less reader-oriented devices such as meta-discourse markers (i.e. attitudinal markers).

Further, Babaii, Atai, and Saidi (2017) examined the three appraisal categories of attitude, graduation, and engagement resources along with their subcategories in 40 English research articles published in Science and Nutrition. Their findings showed that the use of attitude resources followed by graduation and engagement were more abundant in their corpus. Moreover, the frequency of force resources was higher than focus in English popular science articles. Also, the scientists made an attempt to achieve proximity using some lexico-grammatical resources of grading the appreciation. The writers suggested the authors of popular science articles should highlight the intensity or amount of attribute through the use of force resources.

In a cross-linguistic research, Fitriati and Solihah (2019) studied the appraisal resources of attitude, graduation, and engagement in the introduction section of English research articles written by Indonesian and Chinese writers. To this end, they analyzed twenty research articles (ten in each corpus) using Martin and White's (2005) model. Their findings 
showed that the appreciation in attitude resources, expansion in engagement resources, and force in graduation resources were the most frequently used devices in both Chinese and Indonesian corpora. Moreover, their findings showed that Indonesian English writers used appraisal resources of attitude and engagement more frequently than Chinese writers.

The present study aims to investigate graduation resources employed by authors of international journals in developing the conclusion sections of research articles in psychology (as a representative of soft science) and industrial engineering (as a representative of hard science). As a less researched section of research articles (Sheldon, 2018), conclusion section presents the value of the contribution a study makes to the area of knowledge. Moreover, the study of different disciplines offer insights as to how writers communicate and present knowledge to their target audience (Becher \& Trowler, 2001). According to Omidian, Shahriari, and Siyanova-Chanturia (2018), different disciplines negotiate knowledge through a type of discourse that represents both the norms of their community and expectations of its member. The hard-soft categorization, explained above, presents differences in the ways writers fulfill the communicative functions in their writing (Durrant, 2017). Some studies have examined hard and soft sciences in various topics such as genre analysis (e.g., Hu \& Liu, 2018), meta-discourse markers (e.g., Abdel Salam, 2018), grammatical subject (e.g., Ebrahimi \& Heng, 2018), and lexical cohesion (e.g., Shahrokhi, Sadeghi, \& Amiri, 2013) the focus of which was to investigate variations in the use of strategies across disciplines.

Moreover, many studies have taken into consideration attitude resources of appraisal (e.g., Jalilifar, Bardideh, \& Shooshtari, 2018; Li, 2016) and engagement resources (e.g., Amornrattanasirichok \& Jaroongkhongdach, 2017; Pascual, 2010; Rahman, 2018) in academic publication. However, no research has examined graduation resources of conclusion sections of research articles in a cross-disciplinary study.

Thus, the present research was carried out to cover the gap with the following objectives guiding the study:

1) To examine the evaluative strategies used in the conclusion sections of research articles in the field of psychology and industrial engineering as representatives of soft and hard sciences

2) To examine whether there are any significant differences in the use of evaluative strategies between the two corpora

To be able to address the above stated objectives, the following research questions were posed:

1) What evaluative strategies are used in the conclusion sections of research articles in the field of psychology and industrial engineering as representatives of soft and hard sciences?

2) Are there any significant differences in the use of evaluative strategies between the two corpora?

\section{Methodology}

\subsection{Design}

This descriptive study employed both qualitative and quantitative methods to explore evaluative strategies used in two distinct academic disciplines, namely, 'soft' and 'hard' sciences. A qualitative approach was adopted to extract the first 20,000 words from conclusion sections in the corpora for subsequent analysis and annotation. Also a quantitative approach was followed to tally the frequency of the occurrence for each graduation category within Martin and White's (2005) framework. Next, the outputs were compared to see whether there were any significant differences in the distribution of the category across the corpora.

\subsection{Corpus of the Study}

The corpus of the study featured 160 English research articles were selected from psychology as a representative of soft science and industrial engineering as a representative of hard science journals. The articles were published in leading journals published by internationally recognized publishers. They were randomly selected from those published from 2005 to 2017, all empirical studies having conclusion section as an individual section in the article. The major criterion for selecting these journals was the rigorous peer review process all submitted articles went through to ensure the scientific quality of the published ones. Table 1 displays the distribution of research article sections in the corpus. 
Table 1. Distribution of research article sections in the soft and hard discipline

\begin{tabular}{|c|c|c|c|c|}
\hline \multirow{2}{*}{ Articles sections } & \multicolumn{2}{|c|}{ Psychology } & \multicolumn{2}{|c|}{$\begin{array}{c}\text { Industrial } \\
\text { Engineering }\end{array}$} \\
\hline & $\mathrm{F}$ & $\%$ & $\mathrm{~F}$ & $\%$ \\
\hline Introduction, method, result, discussion, conclusion & 69 & 86.25 & 12 & 15 \\
\hline Introduction, method, result \& discussion, conclusion & --- & --- & 3 & 3.75 \\
\hline Introduction, method, result, discussion \& conclusion & 2 & 2.5 & --- & --- \\
\hline Introduction, method, result, conclusion & 9 & 11.25 & 65 & 81.25 \\
\hline Total & 80 & 100 & 80 & 100 \\
\hline Word count in each discipline & 20 , & & 20 , & \\
\hline
\end{tabular}

As shown in Table 1, all empirical research articles in the two disciplines (80 articles in each) consisted of at least introduction, method, results, and conclusion sections. The majority of industrial engineering research articles $(81.25 \%)$ were devoid of discussion sections, whereas almost $86 \%$ of psychology research articles had five distinct sections.

\subsection{Data Analysis}

For data analysis, taking a qualitative approach, the first 20,000 words extracted from conclusion sections in each corpus were selected for data analyses and subsequently annotated based Graduation in Appraisal Theory (Martin \& White, 2005). In order to ensure efficient calculation of word frequencies and accuracy of statistical analyses, the corpus was fed into UAM Corpus Tool version 3. UAM Corpus tool (2.8/3) developed by Mick O'Donell is a common computer-based tool for the qualitative and quantitative analysis of appraisal (Oteíza, 2017).

The data were manually annotated for each sentence with a detailed examination. During the coding process, the researchers read back and forth between clause and text levels and resorted to the co-text to identify the evaluating meanings of cases. To minimize the level of subjective judgment, the encoded data sample was reviewed by another coder for a consistency check. For this purpose, the second coder annotated $10 \%$ of the data independently and the categories were checked among coders to ensure agreement on the annotated data. The coders discussed the cases of disagreement, finally reaching $95 \%$ of agreement in the coded classification. The process of codification took around four months.

Figure 1 presented in review of the literature section outlines Martin and White's (2005) framework of evaluative language with a focus on graduation. This model provides a theoretical framework for a comprehensive study of evaluative stance in conclusion sections of research articles. The theory makes it possible to identify the linguistic features related to the graduation resources. At the same time, it enables different aspects of evaluation, especially manipulation of the strength or weakness of attitudinal value and the construction of interpersonal meaning (Hood, 2004). The coding scheme of graduation resources consists of the following dimensions: first, grading types as 'force' or 'focus', and their subcategories; second, grading orientation as 'up-scaling' or 'down-scaling'; third, grading effect as evoking attitude or not, and if yes, coding the attitude types and polarity of the evoked attitude; if not, coding the particular effect of the non-attitude-evoking graduation (Figure 2). 


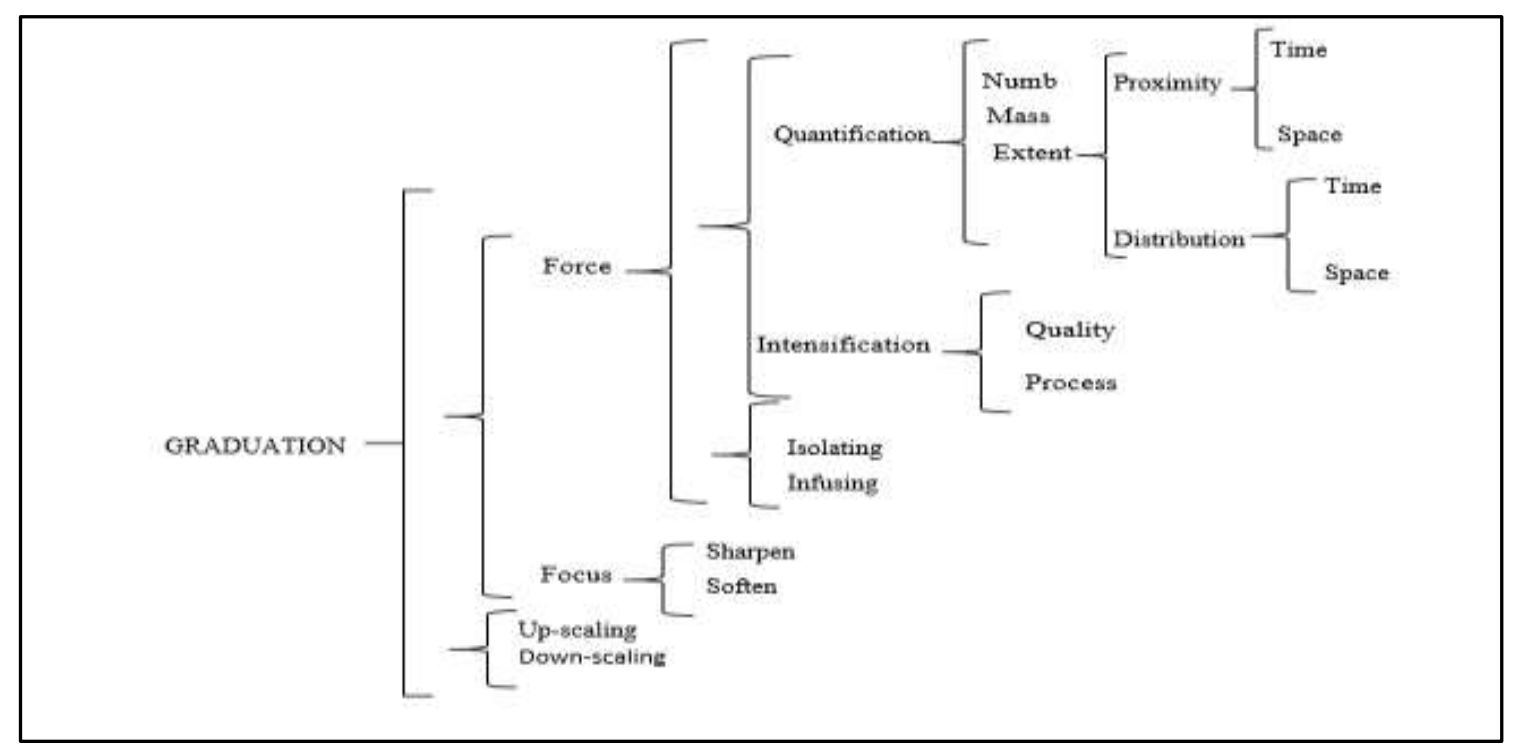

Figure 2. The network of graduation (adopted from Martin \& White, 2005)

By means of quantitative approach adopted in this study, the frequency of the occurrence for each category was produced by UAM corpus tool and the outputs were compared to see whether there were any significant differences in the distribution of each Graduation category across the data.

\section{Results}

In what follows, the findings are presented based on the categories and subcategories in graduation types of the Appraisal Model.

\subsection{Graduation and Non-Graduation Words}

The graduation words are values that can be graded or scaled up or scaled down. In this corpus, the numerical calculation of the words in each corpus is equivalent to 20,000 . Out of 20,000 words, a number of 547 words (2.7\%) were recognized as graduation types in the corpus of soft science (psychology) and 2,203 words (11.0\%) were found as graduation types in the corpus of hard science (industrial engineering). The numerical representation of the use of graduation resources is shown in Table 2 .

Table 2. Graduation and non-graduation words in soft and hard sciences

\begin{tabular}{|c|c|c|c|c|c|c|c|}
\hline \multirow[t]{2}{*}{ Feature } & \multicolumn{2}{|l|}{ Psychology } & \multicolumn{2}{|c|}{ Industrial Engineering } & & \multirow[t]{2}{*}{$\mathrm{X} 2$} & \multirow[t]{2}{*}{ Sig. } \\
\hline & Frequency & $\%$ & Frequency & $\%$ & & & \\
\hline Graduation & 547 & 2.7 & 2,203 & 11.0 & & & \\
\hline Non-Graduation & 19,453 & 97.3 & 17,797 & 89.0 & & $1,070.833$ & $<.001$ \\
\hline Total & 20,000 & 100.0 & 20,000 & & 100.0 & & \\
\hline
\end{tabular}

As shown in Table 2, the number of graduation words in the hard science $(n=2,203)$ is greater than that of the soft science $(\mathrm{n}=547)$. Results of chi-square analyses confirmed a statistically significant difference in the use of graduation words in the two corpora (sig. $=0.00, \mathrm{p}$ value $<.0 .05$ ) 


\subsection{Graduation Types}

The first main subcategory of graduation is 'force' which deals with assessments related to degree of intensity and amount. The second main subcategory of graduation is 'focus' which shows only a marginal/non-prototypical membership in the graduation. Table 3 presents occurrence of force and focus in the two corpora.

Table 3. Graduation types in soft and hard sciences

\begin{tabular}{lclllll}
\hline \multirow{2}{*}{$\begin{array}{c}\text { Feature } \\
\text { type }\end{array}$} & Graduation-Psychology & \multicolumn{2}{l}{ Industrial Engineering } & & Chi-square & Sig. \\
Force & Frequency & $\%$ & Frequency & $\%$ & & \\
Focus & 368 & 67.30 & 1658 & 75.19 & & \\
Total & 179 & 32.70 & 545 & 24.81 & 14.405 & $<.001$ \\
\hline
\end{tabular}

As shown in Table 3, the occurrence of force in psychology amounted to $67.30 \%$ of the corpus while it constituted $75.19 \%$ of the industrial corpus. Moreover, the distribution of focus was $32.70 \%$ and $24.81 \%$ in psychology and industrial engineering corpus, respectively. Results of inferential statistics displayed that there is a statistically significant difference between the use of graduation types in the two corpora (sig. $=.001$, p-value: <0.05). Examples of force and focus elicited from the corpus are as follows:

- Further, our novel experimental design allowed participants even to simultaneously learn bidirectional control over two functionally distinct brain regions (excerpt from soft science corpus).

- Successful replication of this basic finding in a clinical sample of emetophobic patients may also provide fresh clues for clinical interventions (excerpt from hard science corpus).

In these examples, the word functionally belongs to the category of force and is a premodification of adjective distinct, and the word successful belongs to the category of focus under the subcategory of sharpen.

\subsection{Force Types}

The 'force' type is further divided into 'intensification' and 'quantification (Figure1). Intensification has to do with scaling of qualities and processes. Assessments of degree of intensity are applicable to qualities, processes, or the verbal modalities of likelihood, usuality, inclination, and obligation. Quantification refers to imprecise measuring of number (e.g., a few miles, many miles), mass of entities (e.g., size, weight), and distribution or proximity (e.g., small amount, large amount; nearby mountain, distant mountain) (Martin \& White, 2005). Table 4 presents the results of data analysis for the occurrence of force types in soft and hard science corpora.

Table 4. Force types in soft and hard sciences

\begin{tabular}{lllllll}
\hline Feature & Psychology & & \multicolumn{2}{c}{ Industrial engineering } & X2 & Sig. \\
\cline { 2 - 5 } & Frequency & $\%$ & Frequency & $\%$ & \\
\hline Intensification & 186 & 50.5 & 728 & 43.9 & & \\
Quantification & 182 & 49.5 & 930 & 56.1 & 5.355 & $<.021$ \\
Total & 368 & 100.0 & 1658 & 100.0 & & \\
\hline
\end{tabular}

As illustrated in Table 4, intensification occurred in 50.5\% of the soft science corpus while it was used in $43.9 \%$ of hard science corpus. On the other hand, results displayed that quantification was used in $49.5 \%$ of soft science corpus while it was employed in $56.1 \%$ of the hard science corpus. Results of chi-square analyses displayed statistically 
significant differences in the use of force types in the two corpora (sig. $=0.21, \mathrm{p}$-value $=<0.05$ ). In other words, the frequency of using force types in hard science outnumbered that of soft science. Some examples of intensification and quantification elicited from the corpus of soft science and hard science are as follows:

- Here we demonstrate that mice lacking Npas4 displayed increased levels of anxiety but slightly higher levels of sociability compared to wild type animals in the acute post-stroke period (excerpt from hard science corpus).

- To lower operational costs and retain competitiveness, many enterprises expect to implement the BI system, integrate the internal and external data of the enterprises, interpret the data, and transfer them into useful information (excerpt from hard science corpus).

The word slightly belongs to the intensification category and is a premodification, and the word many belongs to the quantification category under the subcategory of mass.

\subsection{Intensification Types}

Intensification consisted of two subcategories: 'vigor' and 'degree.' The up/down-scaling of verbal processes by means of such grammatical intensifiers as slightly and greatly has been termed 'degree.' Many other types of processes are not scalable and therefore a motion verb cannot be used to scale the intensity of the action. By means of such grammatical adverbs, an alternative to the up-scaling/down-scaling of such processes happens by lexical adverbs which are called 'vigor' (Martin \& White, 2005). Table 5 presents the occurrence of vigor and degree in the corpus.

Table 5. Intensification types in soft and hard sciences

\begin{tabular}{lllllll}
\hline \multirow{2}{*}{ Feature } & & \multicolumn{2}{c}{ Psychology } & \multicolumn{2}{c}{ Industrial engineering } & \multirow{2}{*}{ Sig. } \\
\cline { 3 - 5 } & & Frequency & Percent & Frequency & Percent & \\
\hline Intensification & Degree & 2 & 1.1 & 6 & 0.82 & \\
type & Vigor & 184 & 98.9 & 722 & 99.18 & .668 \\
Total & & 186 & 100.0 & 728 & 100.0 & \\
\hline
\end{tabular}

As displayed in Table 5, the occurrence of degree was observed in $1.1 \%$ of the soft science corpus and $0.82 \%$ of the hard science corpus. On the other hand, vigor was used in $98.9 \%$ of the soft science corpus and $99.18 \%$ of the hard science corpus. Some examples of degree and vigor elicited from the corpus are presented below:

- Several radically divergent implementations of MWQs have been posited within the GB theory (excerpt from hard science).

- Modeling of agricultural sector is so $\underline{\text { loosely }}$ formulated that supplies agricultural unskilled workers (excerpt from hard science).

The word radically belongs to the category of intensification and subcategory of degree and the word loosely belongs to the category of intensification and subcategory of vigor.

\subsection{Quantification Types}

'Quantification' includes scaling with respect to 'amount' (e.g., size, weight, strength, number), and 'extent', with extent covering scope in time and space (e.g., how widely distributed, how long lasting) and proximity in time and space (e. g., how near, how recent). Quantification incorporates three subcategories, namely, 'number', 'mass', and 'extent.' It allows for the imprecise measuring of number and the presence or mass of entities according to such features as their size, weight of mass or presence. Besides, it provides for the imprecise measuring of extent, which deals with scope in time and space and proximity in time and space (Martin \& White, 2005). Table 6 presents the frequency distribution of quantification types across the corpus. 
Table 6. Quantification types in soft and hard sciences

\begin{tabular}{|c|c|c|c|c|c|c|c|}
\hline \multirow[t]{2}{*}{ Feature } & & \multicolumn{2}{|l|}{ Psychology } & \multicolumn{2}{|c|}{ Industrial Engineering } & \multirow[t]{2}{*}{$\mathrm{X} 2$} & \multirow[t]{2}{*}{ Sig. } \\
\hline & & Frequency & Percent & Frequency & $\%$ & & \\
\hline \multirow{3}{*}{$\begin{array}{l}\text { Quantification- } \\
\text { type }\end{array}$} & Number & 48 & 26.4 & 287 & 30.9 & & \\
\hline & Mass & 38 & 20.9 & 205 & 22.0 & 2.123 & .346 \\
\hline & Extent & 96 & 52.7 & 438 & 47.1 & & \\
\hline Total & & 630 & 62202 & 930 & 62202 & & \\
\hline
\end{tabular}

As indicated in Table 6, extent resources were used more frequently in soft science $(52.7 \%)$ than hard science corpus $(47.1 \%)$, number resources were found more frequently in the hard science $(30.9 \%)$ than in the soft science $(26.4 \%)$. Mass resources were also used more frequently in the hard science $(22.0 \%)$ than in the soft science $(20.9 \%)$ corpus. Despite these differences, however, the results of chi-square test showed that there were no statistically significant differences. Some examples of force-quantification types are presented below:

- Still, agriculture represents an important part of the economy in most developing countries (excerpt from hard science corpus).

- To this aim, the present_paper extends the model of Ottaviani et al. (excerpt from soft science corpus).

The word most belongs to the category of quantification and subcategory of mass, and the word present belongs to the category of quantification with subcategory of time.

4.6 Extent Types

'Extend' as a subcategory of quantification is further divided into 'proximity' and 'distribution.' It covers scope in time and space (e. g., how widely distributed, how long lasting) and proximity in time and space (e.g., how near, how recent) (Martin \& White, 2005). Table 7 presents the results of occurrence of extend types in the corpus.

Table 7. Extent types in soft and hard sciences

\begin{tabular}{llllllll}
\hline \multirow{2}{*}{ Feature } & & \multicolumn{2}{c}{ Psychology } & Industrial Engineering & X2 & Sig. \\
\cline { 2 - 5 } & & Frequency & $\%$ & Frequency & $\%$ & \\
\hline Extent- & Proximity & 54 & 56.3 & 168 & 38.36 & \\
gate & Distribution & 42 & 43.8 & 270 & 61.64 & 10.380 & .001 \\
Total & 96 & 100.0 & 438 & 100.0 & & \\
\hline
\end{tabular}

As demonstrated in Table 7, the number of proximity tokens in the soft science $(56.0 \%)$ was greater than the hard science $(38.36 \%)$, while the instances of tokens in the hard science $(61.64 \%)$ outnumbered the ones in the soft science $(43.8 \%)$. Results of chi-square analyses displayed a statistically significant difference in the use of extent types in the two corpora ( $\mathrm{sig} .=.001, p$-value $=<0.05)$. In other words, the number of extent types in hard science was significantly greater than the soft science.

\subsection{Proximity Types}

As argued by Martin and White (2005), 'proximity' as a subcategory of extent is further divided into subcategory of 'time' and 'space.' Time and space can be measured with respect to 'proximity' (e.g., near, far; recent, ancient) or 'distribution' (e.g., long-lasting, short-term; wide-spread, sparse). Table 8 presents the occurrence of time and space in the corpus. 
Table 8. Proximity types in soft and hard sciences

\begin{tabular}{|c|c|c|c|c|c|c|c|}
\hline \multirow[b]{2}{*}{ Feature } & & \multicolumn{2}{|l|}{ Psychology } & \multicolumn{3}{|c|}{ Industrial Engineering } & \multirow[t]{2}{*}{ Sig. } \\
\hline & & Frequency & $\%$ & Frequency & $\%$ & & \\
\hline Proximity & Time & 53 & 98.1 & 167 & & 99.4 & \\
\hline Type & Space & 1 & 1.9 & 1 & & 0.6 & .428 \\
\hline Total & & 54 & 100.0 & 168 & & 100 & \\
\hline
\end{tabular}

As shown in Table 8, the occurrence of time in Industrial Engineering $(n=167)$ is more frequent than Psychology $(n=53)$. Moreover, space only occurred once in the two corpora. Despite this difference, however, results of chi-square analysis displayed that there was not any statistically significant difference in the use of proximity type in the two corpora $($ sig. $=0.428, p$-value $=>0.05)$.

- Nevertheless, it will lead to deposition with chronic long-term activation, straight after deposition the large release of inflammatory cytokines leads to the neuronal degeneration (excerpt from soft science corpus).

- We hypothesize, therefore, that the aberrant up-regulation of Npas4 that accompanies focal cortical ischemia may have implications for post-stroke changes in anxiety and sociability (excerpt from hard science corpus).

The expression straight after belongs to the category of time and the word up belongs to the category of space.

\subsection{Distribution Types}

Martin and White (2005) assume that 'distribution' as the subcategory of 'extent' is related to 'time' and 'space' (e.g., how long-lasting, short-term, wide-spread). Distribution in time refers to periodicity of events and geographic occurrence of events in space, while proximity refers to nearness in space or time (Gastil, 1960). Table 9 presents the results of analysis for occurrence of time and space in the corpus.

Table 9. Distribution types in soft and hard sciences

\begin{tabular}{|c|c|c|c|c|c|c|c|}
\hline \multirow[b]{2}{*}{ Feature } & & \multicolumn{2}{|l|}{ Psychology } & \multicolumn{2}{|c|}{ Industrial Engineering } & \multirow[t]{2}{*}{$\mathrm{X} 2$} & \multirow[t]{2}{*}{ Sig. } \\
\hline & & Frequency & $\%$ & Frequency & $\%$ & & \\
\hline \multirow{2}{*}{$\begin{array}{l}\text { Distribution } \\
\text { type }\end{array}$} & Time & 34 & 81.0 & 203 & 75.2 & & \\
\hline & Space & 8 & 19.0 & 67 & 24.8 & .662 & .416 \\
\hline Total & & 42 & 100.0 & 270 & 100.0 & & \\
\hline
\end{tabular}

As illustrated in Table 9, the number of time tokens in psychology (81.0\%) is greater than the value for industrial engineering (75.2\%), while the occurrence of space in industrial engineering $(24.8 \%)$ is more frequent than psychology (19\%). Despite this difference, however, the result of chi-square test displayed that there was no statistically significant difference in the distribution of time and space in the two corpora $($ sig. $=0.416, p$-value $=<0.05)$. Some examples are as follows:

- Intelligence might be associated with higher myelination and/or a higher axonal density in the connecting the right and left hemispheres and connecting areas within each hemisphere in men (excerpt from soft science corpus).

- Contrary to previous studies which have mostly emphasized tangible goods, it highlights intangible goods or services (excerpt from hard science corpus).

The expression right and left is classified under distribution with the subcategory of space, and previous is classified under distribution with the subcategory of time. 


\subsection{Lexical Fusion Types}

Martin and White (2005) note that 'intensifiers', such as slightly, very, rather are typically classed as 'grammatical' items which are closed set having no referential meaning. However, intensification is also carried out by isolated modifiers called 'lexical' rather than 'grammatical' (e.g., ice cold, crystal clear, dirt poor). Intensifications are divided into two broad lexico-grammatical categories, such as 'isolating' and 'infusing.' Isolation refers to whether the upscaling/down-scaling is realized by an isolated, individual item, or whether the sense of up/down-scaling is fused with a meaning which serves some other semantic function. Table 10 presents the results of analysis for occurrence of isolating and infusing in the corpus.

Table 10. Lexical fusion types in soft and hard sciences

\begin{tabular}{llllllll}
\hline Feature & & \multicolumn{2}{c}{ Psychology } & \multicolumn{2}{c}{ Industrial Engineering } & $\begin{array}{c}\text { Chi- } \\
\text { square }\end{array}$ & Sig. \\
\cline { 3 - 6 } & & Frequency & $\%$ & Frequency & $\%$ & \\
\hline Lexical & fusion & Isolating & 356 & 96.7 & 1592 & 96.0 & \\
types & Infusing & 12 & 3.3 & 66 & 4.0 & .422 & .519 \\
\multirow{2}{*}{ Total } & & 368 & 100.0 & 1658 & 100.0 & & \\
\hline
\end{tabular}

As observed in Table 10, the distribution of isolating in psychology is $96.7 \%$ and in industrial engineering is $96 \%$ of the corpus. Moreover, the occurrence of infusing in psychology is 3.3\% of the corpus while in industrial engineering it is only $4 \%$ of the corpus. Results showed there was not any significant differences in the use of lexical infusion in the two corpora ( $\mathrm{sig} .=0.516$, $\mathrm{p}$-value $=>0.05$ ). Some examples of isolating elicited from the two corpora are as follows:

- Even though subjects successfully processed semantic content and syntactic structure, no distinct, stimuluslocked late positivity was observed (excerpt from soft science corpus).

- The results show that the explained method is a simple and relatively accurate and can be applied effectively in the ultimate strength evaluation of ship hull girders and other box-like structures (excerpt from hard science corpus).

The word successfully is of lexical fusion type under the subcategory of isolating, and relative is of lexical fusion type under the subcategory of infusing.

Scale Types: According to Martin and White (2005), 'scaling' is not considered as a subcategory of force but it is the realized meaning of 'up-scaling' and 'down-scaling' existing in quantification and intensification. In other words, force is related to the degree of downing or upping of the qualities and processes (intensification) or the entities (quantification). Table 11 presents results of analysis for occurrence of up-scaling and downscaling in the corpus.

Table 11. Scale types in soft and hard sciences

\begin{tabular}{|c|c|c|c|c|c|c|c|}
\hline \multicolumn{2}{|l|}{ Feature } & \multicolumn{2}{|l|}{ Psychology } & \multicolumn{2}{|c|}{ Industrial Engineering } & \multirow[t]{2}{*}{ Chi-square } & \multirow[t]{2}{*}{ Sig. } \\
\hline & & Frequency & Percent & Frequency & Percent & & \\
\hline \multirow[t]{2}{*}{ Scale-type } & Upscale & 333 & 90.5 & 1151 & 91.1 & & \\
\hline & Downscale & 35 & 9.5 & 147 & 8.9 & .153 & .696 \\
\hline Total & & 368 & 100.0 & 1658 & 100.0 & & \\
\hline
\end{tabular}

As seen in Table 11, the occurrence of up-scaling in psychology comprised $90.5 \%$ and in industrial engineering amounted to $91.1 \%$ of the corpus. Moreover, the distribution of downscaling was $9.5 \%$ in psychology while the figure for the industrial engineering corpus was $8.9 \%$. Results of chi-square analyses displayed no statistically significant 
difference in the use of up-scaling and downscaling in the two corpora (sig. $=0.699, p$-value $=>0.05$ ). Examples of force type of up-scaling/downscaling from the dataset are as follows:

- Dismissal of the creation of the task is less convincing (excerpt from hard science corpus).

- The finished participants have more precise responses to the stimuli, which contribute to larger peak amplitude without affecting peak latency (excerpt from soft science corpus).

The word less is of scale type with the subcategory of downscaling, and more is of scale type under the subcategory of upscaling.

\subsection{Focus Types}

The second main subcategory of graduation is 'focus.' 'Downscale' or 'soften' as the subcategory of focus represents a marginal membership in the category. 'Upscale' or 'sharpen' as the subcategory of focus reflects 'prototypicality' in the category. Table 12 presents results of analysis for the occurrence of soften and sharpen in the corpus.

Table 12. Focus types in soft and hard sciences

\begin{tabular}{llllllll}
\hline Feature & & \multicolumn{3}{c}{ Psychology } & \multicolumn{3}{c}{ Industrial Engineering } \\
\cline { 3 - 5 } & & Frequency & $\%$ & Frequency & $\%$ & Chi-square & Sig. \\
\hline \multirow{2}{*}{ Focus- } & Soften & 41 & 22.9 & 119 & 21.8 & \\
Type & Sharpen & 138 & 77.1 & 426 & 78.2 & & \\
& Total & 179 & 100.0 & 545 & 100.0 & .090 & .765 \\
\hline
\end{tabular}

As shown in Table 12, the occurrence of soft tokens in psychology was $22.9 \%$ of the corpus while it was $21.8 \%$ of industrial engineering corpus. Moreover, sharpen is used in $77.1 \%$ of the psychology corpus while it was used in $78.2 \%$ of the industrial engineering corpus. Results of chi-square analysis displayed that there was no statistically significant difference between the overall uses of soften and sharpen in the two corpora (sig. $=765, p$-value $=>0.05$ ). Examples from the corpus are as follows:

- This reduced late positivity is interpreted as reflecting less effortful processing demand for updating the current discourse model in case the topic entity has previously be integrated therein (excerpt from soft science corpus)

- However, each DT model has its own specific advantages and limitations, making choice of a particular DT difficult to justify (excerpt from hard science corpus).

The word reduced is of focus type under soften and specific is of focus type under the subcategory of sharpen.

Results of statistical inferences showed that there was not any significant difference between soft and hard science corpus in using intensification type, quantification type, lexical infusion, focus type, proximity type, and scale type. On the contrary, frequency counts in sub-graduation displayed that there was a significant difference in the use of graduation words, graduation type, force type, extent type, between soft and hard science corpus.

\section{Discussion}

Appraisal "as a chunk of text that conveys an instance of appraisal" is a multidimensional concept including 'actors', 'attitude', 'graduation', and 'engagement', the components of which are sometimes difficult to discern in a text (Khoo, Nourbakhsh, \& Na, 2012, p.12). The focus of this study was to examine the graduation resources used in the conclusion sections of psychology as a representative of soft science and industrial engineering as a representative of hard science. Investigating graduation components of appraisal system would help us to better understand how authors construct and negotiate the evaluative stance in general and in the conclusion sections of the disciplines under study in particular. 
The findings showed that both soft and hard science disciplines were characterized by a number of graduation resources that had to do with the grading of attitudinal meanings. The overall findings displayed that the number of graduation words and graduation types were significantly greater in the hard science corpus compared to the soft science one. This implied that the authors of hard science articles attempted to express their appreciation and judgment and report the fluctuation of a specific feature in their findings. The variation in the number of evaluative resources in the dataset can be a representative of the discipline in which the articles are written. According to Swales (1990), the conclusion section is sometimes the coalition of discussion and result sections. The authors present a narrow explanation with a broad explanation in the same paragraph of discussion and conclusion sections. However, the length of this summary depends on the section structure of research articles (Yang \& Allison, 2003). In other words, the authors of the corpus under study in hard science discipline tended to present their attitudinal stance towards their findings immediately after the results were reported. Obviously, this is simply a claim and needs to be subjected to further investigation in future studies on hard and soft science disciplines.

The authors of hard science articles used focus resources more frequently than the authors of soft science articles. In other words, through frequent use of lexico-grammatical resources, the authors tended to express their judgment and evaluation more strongly in the conclusion section. The 'force' as a device to shift the degree of intensity of attitude or "turning up the volume" (Martin, 2000, p.148) was employed by the authors of hard science discipline more frequently than the authors of soft science discipline. Moreover, results showed that the authors of the hard science discipline preferred to use 'focus' devices so as to "sharpen or soften the boundaries of a categorical meaning" (Hood, 2004, p.78). The frequent use of 'proximity resources' by authors of hard science articles displayed their emphasis on "a reader-oriented view of writing", the purpose of which is to make the reader understand the text and talk (Hyland, 2010, p.117). It is assumed that "The concept of proximity helps us to understand how writers position themselves and their work in relation to others, so we can see interpersonality as the rhetorical construction of proximity" (Hyland, 2010, p.117).

The authors of hard science discipline exploited more 'intensification' as nominalized qualities to amplify their attitude more significantly than the authors of soft science discipline. Put another way, the authors of hard science articles attempted to express more strong attitudinal meanings in the development of arguments in their conclusion sections of academic paper and also used more evaluative stances through quantity devices to make their claims and propositions look more cautious. The results further displayed that in developing the conclusion section of a research article, authors in both disciplines laid more emphasis on 'time' and less on 'space'; however, the frequent use of time and space in hard science articles showed that the authors used these resources to "imply a value in terms of relevance and/or generalizability" (Hood, 2004, p.91) [where] "The implied value may be positive generalizabiltiy where the scope is amplified, or it may be positive relevance where the distance is reduced" (Hood, 2004, p.92). The data analyzed in this study show that within academic discourse, writers have the opportunity to encode evaluative stance in their own research paper. Writers make an effort to align their readers with the argument for their own research by means of evaluative stance employed in the study. Finally, the findings of this study are in line with previous research on graduation resources (e.g., Babaii, Atai, \& Saidi, 2017; Fitriati \& Solihah, 2019), in which the force resources were the most frequently used type of strategy in research articles.

The present exploratory and descriptive study examined the evaluative resources used in psychology and industrial engineering conclusion section of research articles. The findings showed variations in the use of graduation resources across the corpus which implied the possibility of application of different resources in developing conclusion sections of research articles with variation of disciplines. The results provide significant pedagogical implications for academic settings including language learners and material developers.

Writing an evaluative research article has proved problematic for L2 novice writers while developing academic writing ability is one of the essential skills and abilities language learners need to accomplish. According to Hood (2004), explaining evaluative stance can provide insights and resources for teachers of academic English literacy to abet the learners in incorporating evaluative strategies when preparing academic research papers as well as building effective negotiation with their learners.

The importance of English academic writing has been widely acknowledged by practitioners (e.g. Ghaemi \& Sarlak, 2015; Sadeghi \& Tahririan, 2014); nevertheless, it is difficult to write an English academic writing in an appropriate style (Mizusawa, 2010). In this respect, non-native speakers of English in different academic disciplines should be instructed as to the attitudinal and persuasive strategies in their argumentative research papers. The findings of this 
study can be of significance in English for General Academic Purposes (EGAP) courses in that they can be built on in order to teach students how academic articles are filled with evaluative language in the form of "a wide range of explicit linguistic and non-linguistic resources" (Jalilifar, Hayati, \& Mashhadi, 2012, p.83), and how authors in diverse disciplines make use of lexico-grammatical resources to negotiate meaning and develop different sections of their research articles. In this respect, developing task-based activities where students are asked to evaluate the language of academic publications in various disciplines may raise their awareness as to how linguistic rescores are used to negotiate meaning and build a relationship with the reader.

\section{Conclusion}

Informed by the Appraisal theory, the present cross-disciplinary study analyzed 'graduation' in conclusion sections of research articles. Appraisal theory, focusing on graduation, has contributed to the present study by exploring the possibilities of linguistically achieving an evaluative stance in the conclusion sections on soft science and hard science disciplines. The findings show that there were variations in the use of graduation resources in the two corpora. Results show that force types were more frequently used in industrial engineering than psychology research articles. In other words, hard science writers have a tendency to express their attitude using quantification or intensification devices. This variation in the two disciplines could be attributed to factors such as "readers' expectations, norms and conventions of the academic discourse community, the institutionalized nature of academic discourse, and disciplinary culture" (Dahl, 2004; Li \& Wharton, 2012, cited in Amornrattanasirichok \& Jaroongkhongdach, 2017, p.235).

Although this study provided insights into the use of evaluative strategies in different disciplines, the results should be treated with some caution. First, the research scope was limited to examining only research article conclusion sections. Also, this research has been limited to the study of evaluative strategies in a single language, i.e., English, and is focused on only Graduation subsystem of appraisal theory. Therefore, investigating the authors' evaluative strategies in writing other sections of academic articles, i.e. introduction and discussion sections is recommended. Further cross-cultural or comparative studies of academic texts in other languages are definitely needed to shed more light on differences and similarities in the organization of different sections of research articles. Lastly, it is hoped that future studies will examine other aspects of appraisal model, i.e. attitude or engagement resources, across a variety of disciplines to develop a more comprehensive understanding of how these resources are presented in different contexts.

\section{References}

Abdel Salam El-Dakhs, D. (2018). Why are abstracts in $\mathrm{PhD}$ theses and research articles different? A genre -specific perspective. Journal of English for Academic Purposes, 36, 48-60. https://doi.org/10.1016/j.jeap.2018.09.005

Amornrattanasirichok, A., \& Jaroongkhongdach, S. (2017). Engagement in literature reviews of Thai and international research articles in applied linguistics. Online Proceedings of the International Conference: DRAL 3/19th ESEA 2017, 312-327. http://sola.kmutt.ac.th/dral2017/proceedings/5-6Additional/312327_Engagement $\% 20 \mathrm{in} \% 20$ literature\%20reviews_Supattra\%20Amornrattanasirichok\%20and\%20\%20Wora vut\%20Jaroongkhongdach.pdf

Akinci, S. (2016). A cross-disciplinary study of stance markers in research articles written by students and experts. Unpublished masters' thesis. Iowa State University. http://lib.dr.iastate.edu/etd/15144

Alcaraz-Ariza, M. Á. (2002). Evaluation in English-medium medical book reviews. International Journal of English Studies, 2(1), 137-153.doi: https://doi.org/10.6018/ijes/2011/1/137141

Babaii, E., Atai, M. R., \& Saidi, M. (2017). Are scientists objective? An investigation of appraisal resources in English popular science articles. Iranian Journal of Language Teaching Research, 5(1), 1-19. https://www.researchgate.net/publication/312580984_Are_scientists_objective_An_investigation_of_apprais al_resources_in_English_popular_science_articles

Becher, T., \& Trowler, P. (2001). Academic tribes and territories: Intellectual enquiry and the culture of disciplines. $\left(2^{\text {nd }} E d\right)$. Buckingham: Open University Press.

Bellés-Fortuño, B. (2017). A contrastive study between English and Spanish university lectures. Languages in Contrast, 18(2), 155-174. doi: 10.1075/lic.15018.bel 
Biglan, A. (1973). The characteristics of subject matter in different academic areas. Journal of Applied Psycholinguistics, 57(3), 195-203. http://dx.doi.org/10.1037/h0034701

Dahl, T. (2004). Textual metadiscourse in research articles: a marker of national culture or of academic discipline? Journal of Pragmatics, 36(10), 1807-1825. https://doi.org/10.1016/j.pragma.2004.05.004

Durrant, P. (2017). Lexical bundles and disciplinary variation in university students' writing: Mapping the territories. Applied Linguistics, 38(2), 165-193. doi: 10.1093/applin/amv011

Ebrahimi, S. F., \& Heng, C. S. (2018). Grammatical subject in results and discussion section of research articles: Disciplinary variations. Journal of Teaching Language Skills, 27(1), 97-125. doi: $\underline{10.22099 / j t l s .2018 .30374 .2557}$

Fernandes, A. (2011). Appraisal of evaluative language in people with phasia's Cinderella Narratives. Unpublished Master Thesis, University of Groningen.

Fitriati, S. W., \& Solihah, Y. A. (2019). Non-native writers and the use of appraisal resources in research article introductions. Indonesian Journal of Applied Linguistics, 8(3), 638-645. doi: 10.17509/ijal.v8i3.15265

Gastil, R. G. (1960). The distribution of mineral dates in time and space. American Journal of Science, 258(1), 1-35. http://www.ajsonline.org/content/258/1/1.abstract

Ghaemi, F., \& Sarlak, H. (2015). A critical appraisal of ESP status in Iran. International Journal of Language Learning and Applied Linguistics World, 9(1), 262-276. https://docs.wixstatic.com/ugd/6bee84 552d1ca5c28a416c81592f0283a00112.pdf

Halliday, M. A. K. (1994). An introduction to functional grammar. London: Edward Arnold.

Hood, S. (2004). Appraising research: Taking a stance in academic writing. PhD Thesis, Faculty of Education, University of Technology, Sydney, Australia. Retrieved online from: http://grammatics.com/appraisal/suehoodphd/hoods-phd-links.htm

Hu, G., \& Liu, Y. (2018). Three minute thesis presentations as an academic genre: A cross-disciplinary study of genre analysis. Journal of English for Academic Purposes, 35, 16-30. https://doi.org/10.1016/j.jeap.2018.06.004

Hyland, K. (2005). Stance and engagement: a model of interaction in academic discourse. Discourse Studies, 7(2), 173-192. doi/pdf/10.1177/1461445605050365

Hyland, K. (2008). Persuasion, interaction, and the construction of knowledge: Representing self and others in research writing. International Journal of English Studies, 8(2), 1-23. Retrieved from https://revistas.um.es/ijes/article/view/49151

Hyland, K. (2010). Constructing proximity: Relating to readers in popular and professional science. Journal of English for Academic Purposes, 9(2), 116-127. doi: 10.1016/j.jeap.2010.02.003

Hyland, K. (2011). Academic discourse. In K. Hyland, \& B. Paltridge (Eds.), Continuum companion to discourse analysis (pp. 171-184). London/New York: Continuum International Publishing Group.

Hyland, K., \& Tse, P. (2004). Metadiscourse in academic writing: A reappraisal. Applied Linguistics, 25(2), $156-177$. doi: 10.1093/applin/25.2.156

Jalilifar, A., Bardideh, A., \& Shooshtari, Z. (2018). From academic to journalistic texts: A qualitative analysis of the evaluative language of science. Journal of Teaching Language Skills (JTLS), 37(1), 127-158. doi: 10.22099/jtls.2018.30299.2554

Jalilifar, A., Hayati, M., \& Mashhadi, A. (2012). Evaluative strategies in Iranian and international research article introductions: Assessment of academic writing. Journal of Research in Applied Linguistics, 3(1), 81-109. http://rals.scu.ac.ir/article_10373.html

Johns, C., Chapman, M., \& Woods, P. C. (1972). The characteristics of the literature used by historians. Journal of Librarianship and Information Science, 4(3), 137-156. doi: 10.1177/096100067200400301 
Khoo, C. G., Nourbakhsh, A., \& Na, J. (2012). Sentiment analysis of online news text: A case study of appraisal theory. Online Information Review, 36(6), 1-18. https://doi.org/10.1108/14684521211287936

Li, X. (2016). An attitudinal analysis of English song discourse from the perspective of appraisal theory. Journal of Language Teaching and Research, 7(3), 559-565. doi: http://dx.doi.org/10.17507/jltr.0703.17

Li, T., \& Wharton, S. (2012). Metadiscourse repertoire of L1 Mandarin undergraduates writing in English: a crosscontextual, cross-disciplinary study. Journal of English for Academic Purposes, 11(4), 345-356. https://doi.org/10.1016/j.jeap.2012.07.004

Liu, X. (2010). An application of appraisal theory to teaching college English reading in China. Journal of Language Teaching \& Research, 1(2), 133-135. doi:10.4304/jltr.1.2.133-135

Liu, X. (2013). Evaluation in Chinese university EFL students' English argumentative writing: An appraisal study. Electronic Journal of Foreign Language Teaching, 10(1), 40-53. $\underline{\text { http://e- }}$ flt.nus.edu.sg/archive/v10n12013.html

Liu, X., \& McCabe, A. (2018). Attitudinal evaluation in Chinese university students' English writing: A contrastive perspective. Singapore: Springer. doi: 10.1007/978-981-10-6415-9

Liu, X., \& Thompson, P. (2009). Attitude in students' argumentative writing: A contrastive perspective. Language Studies Working Papers, 1, 3-15. https://www.reading.ac.uk/web/files/english-language-andliterature/ell language Liu and Thompson_vol_1.pdf

Llinares, A. (2015). The interpersonal function of language in CLIL secondary education: Analysis of a spoken and written corpus (INTER-CLIL). European Journal of Applied Linguistics, 3(2), 343-347. doi: https://doi.org/10.1515/eujal-2015-0003

Martin, J. R. (1997). Analyzing genre: Functional parameters. In F. Christie \& J. R. Martin (Eds.), Genres and institutions: Social processes in the workplace and school (pp. 3-39). London, UK: Cassell.

Martin, J. R. (2000). Beyond exchange: Appraisal systems in English. In S. Hunston \& G. Thompson (Eds.), Evaluation in text: Authorial stance and the construction of discourse (pp. 142-175). Oxford: Oxford University Press.

Martin, J. R., \& Rose, D. (2007). Working with discourse: Meaning beyond the clause (2 ${ }^{\text {nd }}$ edition). London: Continuum.

Martin, J. R., \& White, P. R. (2005). The language of evaluation: Appraisal in English. London: Palgrave Macmillan.

Mei, W. S., \& Allison, D. (2003). Exploring appraisal in claims of student writers in argumentative essays. Prospect, 18(3), 71-91. https://www.semanticscholar.org/paper/Exploring-appraisal-in-claims-of-student-writers-inMei-Allison/a9f6c67bd6786548a6570a09b3e166b5af0c5db4

Millán, E. L. (2014). The projection of critical attitude in research article introductions by Anglo-American and Spanish author. RevistaCanaria de EstudiosIngleses Año, 2(1), 137-153. https://dialnet.unirioja.es/servlet/articulo?codigo $=5002745$

Mizusawa, Y. (2010). Language use in English academic writing by a tertiary overseas student. Juntendo Health and Sports Science Research, 1(4), 494-501. https://www.juntendo.ac.jp/hss/sp/albums/abm.php? f=abm00008387.pdf\&n=vol16_p494.pdf

Mori, M. (2017). Using the Appraisal framework to analyze source use in essays: a case study of engagement and dialogism in two undergraduate students' writing. Functional Linguist, 4(11), 1-22. https://doi.org/10.1186/s40554-017-0046-4

Myskow, G., \& Ono, M. (2018). A matter of facts: L2 writers' use of evidence and evaluation in biographical essays. Journal of Second Language Writing, 41, 55-70. https://doi.org/10.1016/j.jslw.2018.08.002

Munday, J. S. (2015) Engagement and graduation resources as markers of translator/interpreter positioning. Target, 27 (3), 406- 412. https://doi.org/ 10.1075/target.27.3.05mun 
Ngo, T., \& Unsworth, L. (2015). Reworking the appraisal framework in ESL research: refining attitude resources. Functional Linguistics, 2(1), 1-24. doi: 10.1186/s40554-015-0013-X

Omidian, T., Shahriari, H., \& Siyanova-Chanturia, A. (2018). A cross-disciplinary investigation of multi-word expressions in the moves of research article abstracts. Journal of English for Academic Purposes, 36, 1-14. https://doi.org/10.1016/j.jeap.2018.08.002

Oteíza, T. (2017). The appraisal framework and discourse analysis. In T. Bartlett, G. \& O'Grady (Eds.). The Routledge handbook of systemic functional linguistics (pp.457-472). London: Routledge.

Pascual, M. (2010). Appraisal in the research genres: An analysis of grant proposals by Argentinean researchers. RevistaSigos, 43(73), 261-280. https://scielo.conicyt.cl/scielo.php?script=sci_abstract\&pid=S071809342010000200004\&lng=es\&nrm=iso\&tlng=en

Põldvere, N., Matteo, F., \& Carita, P. (2016). A study of dialogic expansion and contraction in spoken discourse using corpus and experimental techniques. Corpora, 11(2), 191-225. doi: 10.3366/cor.2016.0092

Rahman, R. F. (2018). Engagement systems in the introduction sections of international journal articles. Proceeding of the 65th TEFLIN International Conference, Universitas Negeri Makassar, Indonesia 12-14 July 2018, 65(1), 261-265. https://ojs.unm.ac.id/teflin65/article/view/6282/3621

Sadeghi, E., \& Tahririan, H. (2014). ESP for psychology and law tertiary level students: Attitudes, challenges and obstacles. Research in English Language Pedagogy, 2(2), 62-77. http://relp.khuisf.ac.ir/article 533614.html

Shahrokhi, M., Sadeghi, A., \& Amiri Dehnoo, M. (2013). Lexical cohesion patterns in research articles: Hard science vs. soft science disciplines. International Journal of Social Science \& Education, 4(1), 196-204. https://www.semanticscholar.org/paper/Lexical-Cohesion-Patterns-in-Research-Articles\%3A-vs.-Shahrokhi$\underline{\text { Sadeghi/cdb8f9ea713e616af56245e0c57bb20df1ac8147 }}$

Sheldon, E. (2018). Knowledge construction of discussion/conclusion sections of research articles written by English L1 and L2 and Castilian Spanish L1 writers. Journal of English for Academic Purposes, 37, 1-10. https://doi.org/10.1016/j.jeap.2018.11.002

Su, W., \& Hunston, S. (2019). Adjective complementation patterns and judgment: Aligning lexical-grammatical and discourse-semantic approaches in appraisal research. Text \& Talk, 39(3), 415-435. https://www.degruyter.com/view/j/text.2019.39.issue-3/text-2019-2031/text-2019-2031.xml

Swales, J. (1990). Genre analysis: English in academic and research settings. Cambridge University Press.

Thompson, G., \& Yiyun, Y. (1991). Evaluation in the reporting verbs used in academic papers. Applied Linguistics, 12(4), 365-382. https://doi.org/10.1093/applin/12.4.365

Taboada, M., Carretero, M., \& Hinnell, J. (2014). Loving and hating the movies in English, German and Spanish. Languages in Contrast, 14(1), 127-161. doi: 10.1075/lic.14.1.07tab

White, P. R. (1998). Telling media tales: The news story as rhetoric. Unpublished doctoral dissertation, University of Sydney, Australia.

White, P. R. (2002). Appraisal-the language of evaluation and stance. In J. Verschueren, J. Östman, J. Blommaert, \& C. Bulcaen (Eds.), The handbook of pragmatics (pp.1-23). Amsterdam/Philadelphia: John Benjamin.

$\mathrm{Wu}$, H. (2013). Appraisal perspective on attitudinal analysis of public service advertising discourse. English Language and Literature Studies, 3(1), 55-66. doi: http://dx.doi.org/10.5539/ells.v3n1p55

Wu, S. M., \& Allison, D. (2003). Exploring appraisal in claims of student writers in argumentative essays. Prospect, $18(3)$,

71-91. http://www.ameprc.mq.edu.au/docs/prospect_journal/volume_18 no $3 / 18$ 3 3 5 WuSiewMei.pdf

Yang, R., \& Allison, D. (2003). Research articles in applied linguistics: Moving from results to conclusions. English for Specific Purposes, 22(4), 365-385. doi: https://doi.org/10.1016/S0889-4906(02)00026-1 